https://doi.org/10.7203/Normas.1.4649

\title{
«ME NIEGO A QUE LA I GRIEGA PASE A LLAMARSE YE»: LOS USUARIOS DE INTERNET ANTE LA ORTOGRAFÍA Y EL DICCIONARIO DE LA REAL ACADEMIA ESPAÑOLA
}

\author{
«I'M AGAINST Y BEING CALLED YE»: THE ATTITUDE OF INTERNET USERS \\ TOWARDS ORTHOGRAPHY AND DICTIONARY OF ROYAL SPANISH ACADEMY
}

\author{
Virginia GONZÁLEZ GARCÍA \\ Universitat de València
}

\section{RESUMEN:}

La recepción de las obras normativas académicas por parte de los medios de comunicación y por parte de especialistas en la materia suele ir acompañada de opiniones que aceptan o rechazan las innovaciones que estas proponen, creando mayor o menor polémica. En noviembre de 2010 los medios de comunicación del mundo hispánico presentaban un avance de la Ortografía de la lengua española de la Real Academia Española cuya reacción en las redes sociales no se hizo esperar, de tal manera que la prensa se haría eco de ella, muy pronto, como movimiento contrario a la obra académica. Este hecho resulta novedoso, pues ya no son solo los expertos e intelectuales los que opinan sobre las obras académicas, ahora la voz la tienen los hablantes de español. En este trabajo se pretende recoger las posturas más frecuentes en la red, principalmente en la red social Facebook, con respecto a dos obras principales de la RAE, la Ortografía y el Diccionario, con el fin de determinar cuáles son los elementos que mayor rechazo han causado entre los hablantes de español.

PALABRAS ClAVE: Ortografía (2011), Real Academia Española, actitudes lingüísticas, Diccionario de la lengua española, Facebook, normas académicas, innovaciones ortográficas, incorporaciones léxicas.

\section{ABSTRACT:}

Royal Spanish Academy's books on grammatical rules are usually commented by media and by specialists in the field, so that innovations of those books are either accepted or rejected, what makes it a controversial issue. In November 2010 the media in the Hispanic world submitted a preview of the Royal Spanish Academy's Orthography, and reactions against it in social networks were swift, as shown in media. This is new, since it is not just the experts and intellectuals who speak out on the academic literature. Spanish speakers are the ones who have a voice now. This paper aims to gather the most common attitudes on the Internet, especially on 
social network Facebook, towards two Royal Spanish Academy's main works, the Orthography and the Dictionary, in order to identify the elements that have caused more rejection among Spanish speakers.

KEY WORDS: Orthography (2011), linguistic attitudes, Spanish Dictionary, Facebook, Royal Spanish Academy rules, orthographic innovations, lexical incorporations.

\section{INTRODUCCIÓN}

En la «Presentación» de la última Ortografía de la lengua española de la Real Academia Española, se hace patente la importancia de las tres publicaciones fundamentales de esta institución: la Ortografía, el Diccionario y la Gramática, como obras que regulan la norma de la lengua, basada esta última en «la correcta escritura, el buen uso del léxico y el dominio de las reglas gramaticales». (RAE, 2010: XXVII). Ahora bien, a lo largo de la historia no han faltado detractores de la normativa plasmada en sus obras, casi siempre ilustres autores e intelectuales reconocidos. La oposición a las obras y a la gestión académicas surge desde su misma fundación, de mano del estudioso Luis de Salazar y Castro, seguido de numerosos nombres ilustres, recogidos en un capítulo titulado «La voz hostil a la Academia», en la obra dedicada a la historia de esta institución por Zamora Vicente (1999: 503-529).

A principios de noviembre de 2010 la prensa de habla hispana y otros medios de comunicación se hacían eco de la inminente publicación de la Ortografía de la lengua española de la RAE con un avance de las que, una vez aprobada la obra definitivamente en la Feria del libro de Guadalajara, serían sus novedades más sustanciosas. El trabajo académico, como de costumbre, acarreó ciertas críticas y generó polémica, pero en esta ocasión, además de los intelectuales y expertos lingüistas que mencionaremos más adelante, el fenómeno saltó con fuerza a la calle o, mejor dicho, a la red. Tan solo unos días más tarde de las primeras publicaciones en prensa, diversos diarios ofrecían titulares como los siguientes: «A Facebook no le gusta perder la i griega» (El País, 15/11/2010), «Facebook contra la RAE» (El Mundo, 26/11/2010), «Nueva ortografía de RAE no gusta en Twitter» (El Universal, 10/11/2010).

Redes sociales como Facebook ${ }^{1}$ o Twitter $^{2}$, blogs de opinión, foros anexos a noticias de prensa, etc., todos ellos elementos de la llamada web colaborativa, contribuyen a la gestación de un fenómeno novedoso y dan voz a miles de hablantes que se sienten libres para opinar y mostrar sus inquietudes ante diversos fenómenos relacionados con la norma y uso de la lengua española. La red se convierte así en un

\footnotetext{
${ }^{1}<$ http://www.facebook.com>.

$2<$ http://www.twitter.com>.
}

NoRMAS. REVISTA DE ESTUdIOS LINGÜÍSTICOS HISPÁNICOS, NÚMERO 1 (AÑO 2011):

http://www.uv.es/normas 
observatorio que posibilita el análisis de actitudes lingüísticas y que debe aprovecharse para conocer usos linguísticos y opiniones de los usuarios.

En este trabajo se llevará a cabo un recorrido por las opiniones y comentarios que los hablantes de español vierten en la red acerca de aspectos relacionados con la norma y uso de esta lengua, con el fin de esclarecer sus principales actitudes y preocupaciones lingüísticas. La fuente principal de los datos que se recogen en este artículo surge de páginas y grupos de la red social Facebook, por ser el ámbito en el que se ha obtenido mayor número de datos. No obstante, y en menor medida, se ha recurrido también a otras aplicaciones digitales como Twitter, y diversos foros asociados a noticias publicadas en prensa digital. En este último caso, aunque se han consultado otras fuentes, la mayor parte de los casos estudiados proviene principalmente de El País, pues esta publicación ofrece a los lectores la posibilidad de añadir comentarios a sus noticias, herramienta que es explotada por estos con mucha frecuencia.

En las siguientes líneas, partiremos de una breve descripción de las plataformas Facebook y Twitter y de su poder mediático en la sociedad actual. A continuación, se presentan los datos obtenidos a través de las opiniones de los usuarios de dichas aplicaciones. Se partirá del análisis de toda aquella manifestación referente a la ortografía, ámbito este al que se le dedica un mayor espacio por tratarse del asunto más tratado en la red. Finalmente se efectuará un acercamiento a las actitudes de los hablantes frente a las innovaciones del diccionario académico.

Los ejemplos transcritos aquí, obtenidos del medio digital, se mantendrán intactos, con errores de ortografía en el caso de que los hubiera. Para la selección de los ejemplos y la catalogación de las ideas más frecuentes se ha tenido en cuenta que sean representativos y no hechos aislados en las plataformas estudiadas.

El objetivo final de este trabajo, por lo tanto, es realizar un primer acercamiento que recoja y evalúe, de forma cualitativa, las manifestaciones de los hablantes de español en la red acerca de las innovaciones propuestas por la RAE en su última Ortografía, así como de las incorporaciones léxicas en el $D R A E$ y el valor normativo que se atribuye a ambas obras.

\section{LAS REDES SOCIALES FACEBOOK Y TWITTER}

Facebook se ha convertido en prototipo de sitio de red social y en el más visitado entre las plataformas de características similares. En este caso, se trata de una red de carácter generalista, que pone a disposición de cada usuario diversas herramientas de presentación y de comunicación. Así, los participantes cuentan con la posibilidad de elaborar un perfil con datos personales, susceptible de actualizaciones continuas (por ejemplo, cuando el usuario cambia su lugar de residencia o está de viaje). Se ofrece a 
los usuarios una ventanilla de estado en la que se invita a responder a la pregunta «¿Qué estás pensando?» y en la que, comúnmente, estos insertan información de diversos tipos que no tiene por qué responder necesariamente a esta pregunta, ya que pueden añadir comentarios de cualquier tipo, así como hipervínculos a otras páginas de Internet y a páginas de vídeo o audio, cargar fotografías, etc. En este espacio son muy frecuentes los hipervínculos que remiten a otras aplicaciones como Twitter, blogs que mantiene el usuario, páginas personales o a cualquier otra aplicación de la web, como un artículo de prensa digital. Por otro lado, en su página de perfil el usuario dispone de un apartado llamado muro, donde el resto de sus «amigos» pueden dejar un mensaje que podrá ser visualizado por todos los usuarios con los que compartan conexiones.

La plataforma Facebook ofrece, igualmente, la posibilidad de crear páginas que «son para que las organizaciones, las empresas, los famosos y las marcas difundan información de forma oficial y pública a personas que elijan conectarse con ellos», según apuntan sus creadores en la información de la misma aplicación ${ }^{3}$. Las páginas cuentan con características muy similares a las de los perfiles de usuarios individuales. También se pueden crear grupos, cuya diferencia principal con las páginas es que se puede configurar su privacidad de manera que solo un conjunto de personas determinadas participen en ellos.

En el caso de Twitter, destaca la versatilidad y capacidad de actualización continua de este sitio. El usuario se convierte en seguidor de una serie de personas o entidades y recibe todas las entradas o tweets (del inglés, tweet, 'piar') que estos van publicando. Del mismo modo, puede publicar sus propias entradas o las de otros usuarios (retweet).

Al referirnos a estas dos redes sociales es necesario aludir también al reciente fenómeno del microblogging, consistente en un proceso que tiene lugar en sitios en los que los usuarios pueden escribir textos breves que no superen una cantidad establecida de caracteres (140 en Twitter y 420 en Facebook). Este hecho obliga a menudo a que el mensaje sea conciso y lo más contundente posible.

Como señala Capdevila (2010: 11) la capacidad interactiva de estos medios permite «modificar una conducta, crear nuevos movimientos de opinión, promover manifestaciones, crear grupos de apoyo a causas concretas o conseguir crear una moda que genere el consumo de un determinado producto». Un claro ejemplo de este potencial social se halla en la plataforma Democracia Real Ya, que nació en la red social de Facebook. Asimismo, en el ámbito que nos ocupa, y como veremos a continuación, las redes sociales han contribuido a propagar de forma rápida, entre otras, opiniones contrarias a los postulados de la última Ortografía académica.

\footnotetext{
${ }^{3}<$ http://www.facebook.com>.
}

NORMAS. REVISTA DE ESTUDIOS LINGÜÍSTICOS HISPÁNICOS, NÚMERO 1 (AÑO 2011):

http://www.uv.es/normas 


\section{REACCIONES DE INTELECTUALES Y EXPERTOS ANTE LA ORTOGRAFÍA ACADÉMICA DE 2010}

Antes de estudiar y analizar la recepción que la nueva obra académica ha tenido en la red, parece oportuno esbozar unas breves notas históricas que den cuenta de la antigüedad de las disputas en torno a la disciplina de la Ortografía y sus normativas. Del mismo modo, en este apartado se recogerán las opiniones de expertos más recientes acerca de la última obra académica.

Los estudiosos han mostrado con frecuencia posturas enfrentadas en cuanto a su concepción de la Ortografía, sobre todo a partir de la asunción más o menos tajante de uno de estos dos criterios: el etimologista y el fonetista. En opinión de Martínez (2010: 16):

(...) los enfrentamientos entre ortógrafos no son precisamente infrecuentes y hacen que la ortografía se presente, históricamente, como uno de los principales motivos de polémica en las obras de contenido lingüístico.

La primera Ortografía de la RAE, publicada en 1741, no fue acatada de manera igualitaria entre los filólogos de la época, autores como Gómez Gayoso, Bordazar, Mayans y Terreros (Martínez 2010: 48-59) seguían sus propias doctrinas, discrepantes de la académica en algunos aspectos, de tal manera que, en palabras de Martínez (2010: 59), «la Real Academia Española no era todavía el único referente en materia ortográfica». Una vez la Ortografía hubo adquirido carácter oficial, en 1744, continuó encontrando opositores que abogaban por una reforma ortográfica, entre las que destacan, por su repercusión, las propuestas de Andrés Bello, ya que fueron el germen de la que fue declarada ortografía oficial en Chile, aprobada en 1844, por la Facultad de Filosofía y Humanidades (Martínez, 2010: 71) ${ }^{4}$.

A finales del siglo $\mathrm{XX}$, y lejos de constituir una doctrina elaborada, todos recordaremos el revuelo mediático que causó el discurso de Gabriel García Márquez, con una propuesta de marcado carácter fonetista:

Jubilemos la ortografía, terror del ser humano desde la cuna: enterremos las haches rupestres, firmemos un tratado de límites entre la ge y jota, y pongamos más uso de razón en los acentos escritos, que al fin y al cabo nadie ha de leer lagrima donde diga lágrima ni confundirá revolver con revólver. ¿Y qué de nuestra be de burro y nuestra ve de vaca, que los abuelos españoles nos trajeron como si fueran dos y siempre sobra una? (García Márquez 1997).

La oposición a la doctrina académica, por lo tanto, no es un hecho novedoso y no sorprende que las disputas en torno a esta materia lleguen hasta nuestros días. Interesa, por ello, observar cuáles han sido las repercusiones de la Ortografía de 2010, obra coordinada por Salvador Gutiérrez Ordóñez, con Elena Hernández Gómez como

${ }^{4}$ El lector encontrará información pormenorizada de las propuestas de estos y otros autores en Martínez (2010).

NORMAS. REVISTA DE ESTUDIOS LINGÜÍSTICOS HISPÁNICOS, NÚMERO 1 (AÑO 2011):

http://www.uv.es/normas 
redactora jefa, presentada como una «ortografía coherente, exhaustiva y simple», «razonada»y «didáctica» ((RAE, 2010: XL-XLI) $)^{5}$.

La publicación de la última Ortografía de la lengua española vino seguida de reseñas y resúmenes por parte de especialistas. En ellas se señalan sus virtudes, los aspectos que podrían mejorarse o algunos detalles considerados incongruencias. Así, García (2011: 6-8) no comparte que se haya de cambiar aspectos que no ofrecen tanto problema, como las tildes diacríticas, frente a otros fenómenos que exigirían mayor regularización; igualmente, señala la falta de rigor al renunciar a la utilización de un alfabeto fonético, "sistema que fomenta la confusión entre letras, sonidos y fonemas" (García 2011: 8). Por su parte, otros autores como Sarmiento (2011: 12) ponen en entredicho la claridad de la obra y su pretendido carácter didáctico, pues, en algunos casos el metalenguaje puede entorpecer la comprensión de ciertas nociones complejas para el usuario no especializado, así, la descripción de diptongos e hiatos en la obra, debido al lenguaje utilizado, supone «uno de los escollos con que muchas personas tropiezan incluso con formación universitaria». Lara (2011) presenta toda una reflexión crítica acerca la labor normativa y los términos en que se debe llevar a cabo en el mundo panhispánico debido a su complejidad. Además señala algunas incongruencias en la teoría lingüística en la obra, como la definición que se contempla del término grafema (Lara 2011: 20), y hace especial hincapié en aquellos aspectos que resultan de difícil resolución por las divergencias propias dentro el mundo hispánico, como la transcripción de los extranjerismos, entre otros aspectos:

La escritura del extranjerismo, tal como la plantean, o bien llena de voces en cursiva muchos textos contemporáneos, sobre todo en ciencias y técnicas, o bien supone procesos de hispanización de los vocablos que las comunidades tienden a rechazar. No es con reglas de esa clase como se ha de enriquecer permanentemente la lengua española, sino con una renovación completa de la cultura de la lengua y una mejor comprensión del contacto de los hispanohablantes con todas las comunidades lingüísticas de la Tierra (Lara, 2011: 21).

Estas opiniones recogidas aquí surgen de la pluma de autores especialistas en estudios lingüísticos y resultan fundamentadas y razonadas en su totalidad. Diferentes apelativos deben destinarse a la polémica mediática que intentó suscitar, también a raíz de la publicación de la Ortografía, el académico Javier Marías, quien esgrime argumentos que a nuestro parecer resultan subjetivos y poco fundamentados científicamente. Sus comentarios se acercan más a los de usuarios no especializados que se manifestaron a través de la red, como veremos más tarde, que a los propios de un intelectual preocupado por la lengua. Así, confunde al lector al manejar datos erróneos como el siguiente: «Zeta. La RAE ha decidido que el nombre de esa letra se escriba sólo con $c$, porque con ésta se representa ese sonido -en parte de España- antes de $e$ y de $i »$, e insiste más abajo «No veo, así pues, por qué "zeta” pasa a ser ahora una falta»

\footnotetext{
${ }^{5}$ No es el objetivo de este artículo reseñar la Ortografía académica, por ello remitimos a las obras de Gómez Torrego (2011) y de Aleza Izquierdo (e. p.), que recogen al detalle las novedades de la obra, así como a las reseñas que se mencionan a lo largo de este trabajo.
}

NORMAS. REVISTA DE ESTUDIOS LINGÜÍSTICOS HISPÁNICOS, NÚMERO 1 (AÑO 2011): http://www.uv.es/normas 
(Marías, 2011b). Sin duda el autor ha trabajado con una fuente equivocada, pues en la obra a la que el autor se refiere, la RAE indica claramente: «De estas cuatro formas, la única recomendada hoy es zeta», y un poco más abajo: «Se desaconsejan explícitamente las formas con $c$-, que nunca han cuajado en el uso, probablemente por ir en contra de la tendencia general a que el nombre incluya en su forma la letra designada» (RAE, 2010: 72). Otras puntualizaciones a las recomendaciones académicas se basan en percepciones subjetivas, pues al referirse a la adaptación de ciertas voces extranjeras se permite el uso de adjetivos como «fea», «horterada», carentes del rigor necesario en la crítica de una obra de tales magnitudes.

\section{REACCIONES DE LOS USUARIOS DE LA RED ANTE LA ORTOGRAFÍA ACADÉMICA DE 2010}

Frente a los datos que se han ofrecido anteriormente, que muestran el interés acerca de cuestiones ortográficas por parte de lingüistas e intelectuales, el auge de las redes sociales como foro de opinión y de difusión de ideas nos proporciona datos sobre la recepción de las normas académicas por parte de usuarios no especializados. En este apartado se recogen las actitudes más representativas que tuvieron lugar con posterioridad al anuncio mediático de las novedades ortográficas. Si bien es cierto que no todas las voces encontradas son disidentes y que algunas aplauden la obra académica, la mayoría de los participantes en las páginas de Facebook y en los foros asociados a las noticias de prensa consultadas muestran su desacuerdo, por ello se les dedica aquí mayor atención.

En contraste con las opiniones esbozadas en el epígrafe anterior, que surgen a partir de la lectura de la Ortografía una vez publicada, destaca el hecho de que las reacciones de los internautas en las redes sociales y en foros de opinión tuvieran lugar como respuesta al tratamiento mediático que adelantaba las novedades de la obra académica y manejaran, por lo tanto, rasgos sesgados e incompletos. Como anunciábamos arriba, semanas antes de su aprobación definitiva, los medios de comunicación sintetizaban las que consideraban las mayores novedades de la obra, como es el caso de un artículo de El País (6/11/2010), que avanza los siguientes cambios:

1. La letra $i$ griega se llamará ye; y las letras $b$ y $v$ se llamarán be y uve respectivamente.

2. Ch y $l l$ se consideran dígrafos y pasan a suprimirse del inventario del alfabeto.

3. Se puede prescindir de la tilde en el adverbio solo y en los pronombres demostrativos.

4. Guión, hui, truhan, y otras similares deben escribirse sin tilde por considerarse monosílabas.

NORMAS. REVISTA DE ESTUDIOS LINGÜÍSTICOS HISPÁNICOS, NÚMERO 1 (AÑO 2011):

http://www.uv.es/normas 
5. Desaparece la tilde en la conjunción $o$ cuando aparece entre cifras.

6. Se pasará a escribir Irak, Catar y cuórum.

7. Se producen cambios en las mayúsculas referidas a accidentes geográficos y a cargos.

8. El prefijo ex- se escribirá unido a su base léxica.

Poco después de la difusión en los medios de estas características enumeradas arriba, y antes de que se publicara la edición definitiva, los internautas habían mostrado su oposición a ciertos cambios a través de la creación de múltiples páginas en Facebook y un aluvión de comentarios adscritos a determinadas noticias de prensa. En primer lugar, destaca la página de la que se hicieron eco algunos medios de prensa escrita «Me niego a que "i griega" pase a llamarse "ye"», que cuenta ya con 80958 seguidores, pero este no es un caso aislado, pues son numerosas las páginas o grupos de Facebook que aluden directamente a algún elemento contenido en la nueva Ortografía, cuyos títulos van de lo serio: «Grupo de rechazo a las nuevas reglas ortográficas de la RAE», a lo jocoso o sarcástico: «Para que los actuales miembros de la DRAE dejen la droga». En otros casos llama la atención el recurso frecuente a las metáforas de tipo sociopolítico y en ocasiones bélico, pues se habla de objeción de conciencia, rebeldía, destrucción, insumisión, como se observa en los siguientes ejemplos:

1. «El mecanismo aleatorio y absurdo que utiliza la RAE para destruir la lengua»

2. «Soy un rebelde, sigo acentuando el "sólo" desafiando a la RAE》

3. «Insumisión a los nuevos cambios de la RAE»

4. «Me declaro objetor de conciencia de la nueva ortografía de la RAE» ${ }^{6}$

En estos grupos, los comentarios carecen de moderación y los argumentos razonados para justificar su oposición escasean, pues, en efecto, se percibe el enfrentamiento como una guerra en la que, incluso, habría que rescatar rehenes: hay una página cuyo nombre es « $i$ Di no a la YE! Salvemos la Y (griega)», y hay ganadores y vencidos, pues los usuarios se manifiestan como ganadores una vez se publica la Ortografía y se mantiene la posibilidad del nombre $i$ griega: «hemos ganado», afirma un usuario de Facebook.

Los comentarios de noticias de prensa, el segundo tipo de intervenciones manejado en este trabajo, contrastan por un predominio mayor de actitudes razonadas y un tono que se acerca en mayor media al lenguaje formal, sin duda condicionado por el hecho de aparecer en la página digital de un periódico de prestigio. Destaca igualmente el gran número de participaciones, pues la noticia que se publicó el día 5 de noviembre de 2010 de El País, "La "i griega" se llamara "ye"» tuvo como respuesta 1563

\footnotetext{
${ }^{6}$ La negrita es nuestra.
}

NORMAS. REVISTA DE ESTUdIOS LINGÜÍSTICOS HISPÁNICOS, NÚMERO 1 (AÑO 2011): http://www.uv.es/normas 
comentarios, cantidad que sobrepasa la cuota normal de participación de los lectores en noticias de esta publicación diaria, pues en contadas ocasiones se suele superar el número de quinientos.

En general, en ambos tipos de manifestaciones, Facebook y comentarios de lectores, se hace patente el desconcierto ante las propuestas que se anuncian. Los aspectos más controvertidos resultan estar relacionados con las normas de acentuación, hasta el punto de que, en un artículo de opinión en El País, Salvador Gutiérrez dedica un gran espacio a explicar las decisiones tomadas y a esclarecer el concepto de diptongo ortográfico. Precisamente el artículo llevaba el título de «Guión o guion» (El País, $6 / 02 / 2011)^{7}$.

En el caso de los acentos diacríticos, los usuarios esgrimen sin cesar ejemplos en los que el uso de «solo» o de los demostrativos sin tilde puede inducir a confusión y en general la conclusión les lleva a preguntarse por qué no actuar sobre otros ámbitos que muestran mayores dificultades:

Al final, siento que no somos más que meros observadores de un grupo de gente que decide cosas que no necesitamos que nadie las decida, porque no creo que nos causen problema alguno (comentario en El País, 6/11/2011).

Con respecto al asunto de la acentuación de las palabras monosílabas con diptongo, guion, truhan, fue, los hablantes muestran su desconcierto ante un metalenguaje que les parece críptico y son frecuentes los comentarios que ponen en entredicho la posible pronunciación de estas voces como monosílabas:

Fué es aguda, como amór, alúd, fuét, truán (paso de la h). Así mido las sílabas, eso son naturalmente para mi, no entiendo el diptongo en serio lo digo (comentario en El País, 6/11/2011).

Por otro lado, entre los participantes en estos debates prevalece la idea de que estas modificaciones académicas se llevan a cabo para simplificar la ortografía y la escritura como una concesión a hablantes que no dominan las normas. En ese sentido se formulan muchos de los comentarios que nos encontramos. En definitiva, los hablantes perciben ciertos cambios como medidas que contribuyen a «empobrecer» el lenguaje, ya en proceso de deterioro:

1. Fomentando la incultura y el desvanecimiento de la lengua mas rica del mundo ahora bien con una sociedad como esta que mas da cuanto mas incultos, mejor los llevamos al redil (comentario en Facebook).

2. Como siempre igualando por la cola. Como hay quien no sabe las letras del alfabeto o las pronuncia mal hacemos norma de ese error. Como algunos burros no saben utilizar la tilde diacrítica en la palabra «sólo» ¡a eliminarla tocan! y así no es falta de ortografía. Como muchas personal olvidan acentuar la «o» entre números, pues

${ }^{7}$ Con anterioridad, el académico se había dedicado a esclarecer dudas con respecto a la tilde diacrítica desaparecida a los cambios en estos diptongos (El País, 21/12/2010).

NORMAS. REVISTA DE ESTUDIOS LINGÜÍSTICOS HISPÁNICOS, NÚMERO 1 (AÑO 2011):

http://www.uv.es/normas

(ISSN 2174-7245) 
quitamos la tilde. Sí señor, esto es igualdad, todos burros, todos iguales (comentario en Facebook).

3. Venga! hagamos de nuestro idioma la más mínima y cutre expresión, justo a la medida de los ignorantes que no saben ni hablar, ni escribir y mucho menos qué «cosa extraña» es una tilde.... Solo faltaba que unos académicos promovieran la incultura. Qué vergüenza!! (comentario en Facebook).

4. A mi me parece que esto es en plan: si no puedes erradicar la incultura, acepta las faltas de ortografía de los demás, así parecerá que saben más (comentario en El País, $6 / 11 / 2011)$.

Otra de las decisiones académicas que más ríos de tinta (digital, entiéndase) ha hecho correr ha sido el nombre de la letra y griega. En Facebook, principalmente, destacan actitudes beligerantes y enfervorecidas, muy agresivas verbalmente, que responden a una actitud de inmovilismo. ${ }^{8}$ Los hablantes se niegan a aceptar propuestas que se entienden como absurdas, porque, como señala García (2011: 6):

(...) cuando se toca la grafía que los hablantes han interiorizado como válida y que, adquirida con esfuerzo desde la infancia, constituye una de sus principales seguridades, todo se cuestiona y los recelos se multiplican, especialmente si los cambios no se perciben como absolutamente necesarios.

Esta actitud, por lo que se deduce de lo observado, puede aplicarse igualmente a la posibilidad de que se cambie el nombre de las letras, pues se percibe un alto grado de conservadurismo lingüístico, como se desprende de los siguientes comentarios:

1. Siempre he dicho i griega y no voy a cambiarlo ahora, por que eme gusta así.

2. Me parece una soberana gilipollez que ahora de repente cuando de toda la santa vida se ha llamado Y Griegase le quiera cambiar el nombre. Yo seguiré llamándola y Griega mientras viva que coño «ye» ${ }^{9}$

Otros argumentos con los que se rechazan estas y otras propuestas se centran en cuestiones estéticas:

1. (...) eso es horrible y cateto.

2. (...) guión LLEVA TILDE!! y le queda bonito

En otros casos, de algunos comentarios, lo suficientemente frecuentes como para ser valorados aquí, se desprende una actitud que raya en la xenofobia lingüística y muestra un claro desprecio hacia variedades que se consideran ajenas:

\footnotetext{
${ }^{8}$ Recordemos que los mensajes de Facebook están limitados en número de caracteres, hecho que contribuye a que el mensaje sea no solo conciso, sino, en determinados casos, los más explícito y categórico posible.

${ }^{9}$ Se han mantenido intactos todos los comentarios extraídos de la red. No se han corregido, por lo tanto, los posibles errores de ortografía o escritura que en ellos se encuentran.
}

NORMAS. REVISTA DE ESTUDIOS LINGÜÍSTICOS HISPÁNICOS, NÚMERO 1 (AÑO 2011): http://www.uv.es/normas 
1. ¿Ye? jejeje Y griega, si en otras zonas no aprendieron bien el idioma que usan que acudan de nuevo al cole ;). Es como lo de $\mathrm{v}$ baja y b alta... de pena (comentario en Facebook).

2. Ya nos quitaron la "ch" y ahora la Y griega se tiene que llamar ye... así queremos que el castellano se expanda, así... (comentario en Facebook).

3. tratar de convertir nuestro idioma EL ESPAÑOL en un idioma de otro pais es una autentica vergüenza (comentario en Facebook)

Estas actitudes de etnocentrismo lingüístico dan lugar a enfrentamientos entre hispanohablantes de diferentes países, que merecen ser detallados, pues muestran a los lingüistas que, en materia de panhispanismo, es una asignatura pendiente trabajar las actitudes lingüísticas, como se deduce de la siguiente intervención que suscitará un aluvión de respuestas por parte de hablantes hispanoamericanos.

a) Bueno, bueno... ahora que llamen «ñe» a la eñe, «jo» a la jota y así sucesivamente. Me toca los pelendengues que a veces la RAE tenga la piel tan fina (con razón) y a veces sea capaz de contradecirse con eso de que «sólo es notaria del uso del lenguaje». ¿Quién la llama correctamente "Ye" a excepción de los asturianos? Porque si nos fijamos en algunos sudamericanos acabaremos convirtiendo la

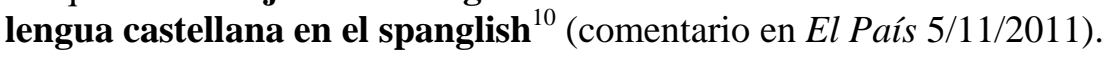

\section{4. «TUS FALTAS DE ORTOGRAFÍA ME IMPIDEN UNIRME A TU GRUPO»}

De lo dicho anteriormente se puede deducir fácilmente que el resumen de la nueva Ortografía ofrecido por los medios de comunicación actuó no solo como detonante de la polémica, sino que además condicionó que los hablantes se centraran en atacar los elementos destacados en los titulares y resúmenes de prensa, sin cuestionarse ninguno de los otros aspectos de la obra. Si bien esto parece ser así, este interés por la ortografía, y concretamente por la representación gráfica de los fonemas y del acento, responde a una realidad que se puede contemplar también en la red y que resulta anterior a la controversia que ha centrado este trabajo. Así, un rastreo por páginas y grupos en redes sociales dedicados a cuestiones lingüísticas destaca que las preocupaciones relacionadas con las faltas de ortografía tenían carta de naturaleza en Facebook antes de que comenzara la polémica de la Ortografía académica.

En nuestro estudio hemos detectado que las páginas más frecuentes y con mayor número de usuarios son aquellas que se dedican a vilipendiar a los que escriben con faltas de ortografía, mientras que son escasas o inexistentes páginas que se refieran a cuestiones como la puntuación, el uso de mayúsculas, etc., pues entre las preocupaciones lingüísticas de los hablantes, encontramos auténticos debates acerca de

\footnotetext{
${ }^{10}$ La negrita es nuestra.
}

NoRMAS. REVISTA DE ESTUdIOS LINGÜÍSTICOS HISPÁNICOS, NÚMERO 1 (AÑO 2011): http://www.uv.es/normas 
la necesidad de usar la lengua con corrección. En general, salvo algunas excepciones del tipo «por los q creen q los acentos y mayusculas son inutiles!», existe una corriente de páginas y grupos que denuncian las faltas de ortografía en los textos digitales, como indican los siguientes grupos, que constituyen una muestra de algunos de los más seguidos:

1. «Tus faltas de ortografía me impiden unirme a tu grupo...».

2. «Sentir un cosquilleo siniestro al mirar horribles faltas de ortografía»

3. «Yo soy de los que escriben los sms con acentos, eñes y puntuación correcta»

Estas páginas, ¿anuncian un cambio de actitud con respecto a los usos lingüísticos frente a la economía lingüística y el descuido propio de los mensajes de $s m s$ ? Es posible que, en algún sentido, así sea, de hecho, en el ámbito empresarial, un experto inglés, Charles Duncombe ${ }^{11}$, ha levantado la voz de alarma con respecto a la corrección escrita en la red y los efectos negativos que la ausencia de esta pueda tener. De ello se han hecho eco en el ámbito hispánico diversas publicaciones digitales y blogs especializados en posicionamiento de páginas, en las que se afirma que una mala ortografía puede materializarse en pérdidas millonarias, de tal manera que se recomienda un mayor cuidado en las páginas, pues la mayor parte de las transacciones comerciales se realiza ya a través de Internet, de forma escrita.

En las redes sociales esta tendencia al cuidado de la forma, que no sabemos en qué medida tendrá mayor o menor éxito en el futuro, queda manifiesta en las páginas enumeradas arriba y en comentarios de Twitter como los siguientes: «1) Imaginación 2) Buena ortografía y 3) Una cuenta en Twitter. Estos son los ingredientes que se necesitan para crear al Tuitero perfecto». De cualquier modo, a este respecto, serán necesarios estudios cuantitativos que evalúen los usos lingüísticos en redes sociales y detecten el grado de corrección de los textos, pues la realidad que se ha hallado en este trabajo muestra que solo una pequeña parte de los escritos estudiados aparecían escritos con corrección, a pesar de que, en muchos de los casos, se critique el empobrecimiento del lenguaje.

\section{LÉXICO Y DICCIONARIO}

Parece claro el predominio de una actitud conservadora entre los hablantes a la hora de rechazar las modificaciones de la Ortografía académica de 2010, como se deduce de las muestras analizadas en este trabajo. En general, se percibe cierta oposición a cambios que no se comprenden y que se consideran innecesarios. Para los hablantes que participaron en esta controversia digital, los cambios ortográficos, por lo menos en los términos que la RAE propone en esta ocasión, suponen un empobrecimiento del idioma y un ataque a la propia cultura. Por otro lado, apenas

\footnotetext{
${ }^{11}<$ http://www.bbc.co.uk/news/education-14130854〉.
}

NORMAS. REVISTA DE ESTUDIOS LINGÜÍSTICOS HISPÁNICOS, NÚMERO 1 (AÑO 2011): http://www.uv.es/normas 
detectamos casos que vayan en la línea de una reforma ortográfica total como la que proponía Gabriel García Márquez. Parece pues, que a los académicos se les pide que no cambien la ortografía.

Cabe ahora preguntarse si sucede lo mismo con el Diccionario de la lengua española. Aunque los aspectos léxicos no mueven en el mismo grado la opinión pública en comparación con los ortográficos, es cierto que los hablantes también manifiestan sus posturas con respecto a algunos elementos, como recientemente ha sucedido con la adaptación de extranjerismos al castellano, polémica suscitada de nuevo por algunos artículos aparecidos en la prensa en los que la voz protagonista era pirsin. (El País, 02/01/2011). En este caso, la mayoría de las opiniones encontradas reivindican que las voces extranjeras se mantengan tal y como son en su lengua de origen, sin adaptaciones gráficas, pues, en general, ciertas adaptaciones les resultan ridículas.

En general esta tendencia conservadora se ha hecho patente en la red ante la aceptación de voces que, generalmente, se consideran vulgares, como sucede con la página de Facebook «Me niego a que "asín", "setiembre" o "cocreta" estén aceptados por la RAE». Este movimiento, que se plasma en algunas páginas más, parece no tener en cuenta la marca vulgar con la que aparece asín en el DRAE, o la remisión de setiembre a la voz septiembre, y por lo tanto, preferida por la RAE. De cualquier modo, parece que esta oposición radical, que también cuenta con un gran número de seguidores, surge de la concepción que se tiene del Diccionario académico como obra normativa y del desconocimiento de la propia filosofía de la obra que no rechaza la inclusión de vulgarismos o voces arcaicas, sino que, ante la imposibilidad de recoger todo el léxico, en el caso de los dialectalismos, tecnicismos, vulgarismos, coloquialismos, arcaísmos, etc., procede a realizar una selección que se centra en recoger aquellos usos más «extendidos o característicos» (RAE, 2001: XXXIII). De nuevo, los hablantes perciben que ciertas decisiones de la RAE empobrecen el lenguaje, $\mathrm{y}$ abundan comentarios que manifiestan estas creencias, de tal manera que, bajo nombres tan confusos como "Yo también estoy en contra de las nuevas acepciones en la RAE» ${ }^{12}$ y caracterizándose a sí mismo como «arcaicos de la RAE, defensores del lenguaje», afirman:

Porque en lugar de preocuparse por recuperar la antigua riqueza de nuestra lengua o tratar de difundirla, se dedican a aceptar los vulgarismos más atroces y, de tanto en tanto, a cambiar el nombre de tal o cual letra... (comentario en Facebook).

Esta actitud vigilante en el caso del léxico que se incorpora al diccionario, proviene de la convicción extendida de que tal o cual palabra "no existe" si no aparece en el diccionario académico o de la creencia en que su uso no está legitimado hasta que se le da entrada en este. Se puede afirmar, con Garriga y Martínez (2005: 59), que «hay un aspecto en el que el diccionario sigue teniendo un poder casi mágico: el reconocimiento de una palabra como parte del léxico de una lengua». En este sentido las principales reivindicaciones de los internautas en Facebook en torno a aspectos léxicos

\footnotetext{
${ }^{12}$ Los creadores del grupo confunden el término acepción con el de voz.
} 
van dirigidas a exigir la incorporación de determinadas voces en el diccionario, porque, según algunos, de esta manera su uso quedaría legitimado, como se observa en grupos como «Por la aceptación de "perroflauta" por la RAE», con argumentos como el siguiente:

En contra de aceptar cosas como «ye» en vez de «i griega», «asín»o «solo» sin acento y en cambio no aceptar palabras como «pagafantas», «porculero» o «perroflauta» en el diccionario que sería lo normal (comentario en Facebook).

En el caso de las actitudes frente al inventario léxico del Diccionario de la RAE, al contrario de lo que sucedía con la ortografía, los hablantes no manifiestan una actitud conservadora predominante, sino que esta se conjuga con una tendencia a exigir que determinadas voces como las citadas en el ejemplo anterior, o como «Facebookear» aparezcan en la obra.

\section{CONCLUSIONES}

El auge de la web colaborativa o web 2.0., en la que los usuarios, como afirma uno de sus fundadores, Tom O'Relly (2006) «añaden valor», ha generado un fenómeno nuevo que abre la vía para múltiples estudios acerca de las creencias y actitudes lingüísticas de los hablantes de español. El medio digital escrito es el cauce que vehicula la expresión de numerosas opiniones acerca de hechos lingüísticos y de los contenidos de obras normativas.

En este trabajo se ha realizado un recorrido panorámico centrado principalmente en la recepción de la Ortografía académica, así como en las posturas acerca de la inclusión o el rechazo de ciertas voces en el DRAE. En el caso de la Ortografía, las redes sociales y la posibilidad de publicar comentarios de determinadas noticias de prensa ha posibilitado que los hablantes viertan su opinión libremente acerca de las novedades que se han ido conociendo principalmente a través de los medios.

Con respecto a la Ortografía, se observa la dificultad para entender ciertas reglas relacionadas con la acentuación de los diptongos ortográficos, la incomprensión de las normas relacionadas con los acentos diacríticos, que se consideraban necesarias. Asimismo, se manifiesta una actitud conservadora en aspectos relacionados con los nombres de las letras, que muestran el arraigo cultural de estos elementos, hasta el punto de que se considera que estas propuestas, de llevarse a cabo, empobrecen la lengua española.

En el caso del Diccionario, se sobreestima o se teme el valor sancionador de la RAE y se considera como una aberración la inclusión de ciertas palabras consideradas vulgares, mientras que se exige que otras voces pasen a formar parte del inventario del diccionario.

NORMAS. REVISTA DE ESTUDIOS LINGÜÍSTICOS HISPÁNICOS, NÚMERO 1 (AÑO 2011):

http://www.uv.es/normas 
Se ha intentado en este trabajo abrir una ventana al rico material que las redes sociales o los foros de opinión ofrecen para trabajar aspectos relacionados con las actitudes lingüísticas. En nuestro recorrido se han detectado algunos aspectos que merecen una atención detallada en el futuro, pues no procede tratarlos ahora, ya que se le alejan un tanto de nuestro objetivo inicial. Se trata de elementos como las actitudes ante las recomendaciones del lenguaje no sexista, la existencia o no de conflicto en torno al nombre de la lengua, castellano o español, o los comportamientos, mínimamente esbozados arriba, que genera la variedad lingüística panhispánica entre los hablantes. De igual modo, resultará interesante indagar en los usos linguísticos de los hablantes, con el objeto de detectar las dificultades más frecuentes y las nuevas tendencias ortotipográficas en la red.

\section{REFERENCIAS BIBLIOGRÁFICAS}

AlezA IZQUIERO, Milagros (e. p.) Signos ortográficos, ortotipografía y normas actuales, Universitat de València, Valencia.

Capdevilla Domínguez, David (2010): «Las Redes Sociales. Tipología, uso y consumo de las redes 2.0 en la sociedad digital actual», Documentación de las Ciencias de la Información, vol. 33, 45-68.

GARCÍA MÁrQUEZ, Gabriel (1997): «Botella al mar para el dios de las palabras». Referencia en línea: 〈http://sololiteratura.com/ggm/marquezdisbotella.htm> [consulta: 17/07/211].

García Mouton, Pilar (2011): «Reflexiones sobre la nueva ortografía», Cálamo FASPE, $\mathrm{n}^{\circ} 57$ - abril-junio, 6-8. Referencia en línea:

<http://www.faspe.org/actividades/publicaciones/273-revista-calamo-faspe-no-57abril-junio-2011.html> [consulta: 17/07/211].

GÓMEZ TORREGO, Leonardo (2011): Las normas académicas: últimos cambios, Madrid, SM.

GutiÉRrez OrdóÑEZ, Salvador (2011): «¿Guión o guion?», El País, 06/02/2011. Referencia en línea:

<http://www.elpais.com/articulo/opinion/Guion/guion/elpepiopi/20110206elpepiopi_12 /Tes> [consulta: 17/07/211].

MARÍAS, Javier (2011a): «Discusiones ortográficas I», El País semanal, 30-012011. Referencia en línea:

$<$ http://www.elpais.com/articulo/portada/Discusiones/ortograficas/I/elpepusoceps/ 20110130elpepspor_14/Tes $>$ [consulta: 17/07/211]. 
MARÍAS, Javier (2011b): «Discusiones ortográficas II», El País semanal, 06-022011. Referencia en línea:

$<$ http://www.elpais.com/articulo/portada/Discusiones/ortograficas/II/elpepusoceps /20110206elpepspor_16/Tes> [consulta: 18/07/211].

LARA, Luis Fernando (2011): «La nueva Ortografía ¿imprescindible? Sí, pero...», La Gaceta, julio, 19-21. Referencia en línea: 〈http://issuu.com/fcechile/docs/jul_2011> [consulta: 18/07/211].

MARTÍNEZ AlCALDE, M. José (2010): La fijación ortográfica del español: norma y argumento historiográfico, Bern, Peter Lang.

O’REILly, Tim (2006): «Qué es 2.0. Patrones del diseño y modelos del negocio para la siguiente generación del software». Referencia en línea:

$<$ http://sociedadinformacion.fundacion.telefonica.com/DYC/SHI/seccion=1188\&idioma $=$ es_ES\&id=2009100116300061\&activo=4.do?elem=2146> [consulta: 18/07/211].

REAL ACADEMia ESPAÑOla Y ASOCIACión DE ACADEMias DE LA LENGUA ESPAÑOLA (2001): Diccionario de la lengua española, Madrid, Espasa-Calpe. Referencia en línea: <http://www.rae.es> [consulta: 28/08/2011].

REAL ACADEMia EsPañola Y ASOCIACión DE ACADEMIAS DE LA LENGUA ESPAÑOLA (2010): Ortografía de la lengua española, Madrid, Espasa-Calpe.

SARMIENTO GONZÁLEZ, Ramón (2011): «La nueva ortografía académica (2010)», Cálamo FASPE, n 57 - abril-junio, 9-13. Referencia en línea:

<http://www.faspe.org/actividades/publicaciones/273-revista-calamo-faspe-no-57-abriljunio-2011.html > [consulta: 18/07/211].

Zamora Vicente, Alonso (1999): Historia de la Real Academia Española, Madrid, Espasa.

ARTÍCULOS DE PRENSA EN FORMATO DIGITAL (por orden cronológico):

«Las academias desestiman la propuesta de la 's' para el plural de las siglas», El País, 02/11/2010. Referencia en línea:

<http://www.elpais.com/articulo/cultura/academias/desestiman/propuesta/s/plural/siglas /elpepucul/20101102elpepucul_4/Tes> [consulta: 15/07/2011].

«La "i griega" se llamará "ye"», El País, 05/11/2010. Referencia en línea: $<$ http://www.elpais.com/articulo/cultura/i/griega/llamara/ye/elpepucul/20101105elpepu cul_9/Tes> [consulta: 15/07/2011]. línea:

«Limpia, fija... y jubila letras y acentos», El País, 06/11/2010. Referencia en <http://www.elpais.com/articulo/cultura/Limpia/fija/jubila/letras/acentos/elpepicul/2010 1106elpepicul_1/Tes> [consulta: 15/07/2011]. 
«Nueva Ortografía de la RAE no gusta en Twitter», El Universal de México, 06/11/2010. Referencia en línea: 〈http://www.eluniversal.com.mx/notas/721523.html> [consulta: 15/07/2011].

«La i griega aún tiene esperanzas», El País, 09/11/2010. Referencia en línea: $<$ http://www.elpais.com/articulo/sociedad/i/griega/tiene/esperanzas/elpepisoc/20101109 elpepisoc_1/Tes $>$ [consulta: 15/07/2011].

«A Facebook no le gusta perder la i griega», El País, 15/11/2010. Referencia en línea:

$<$ http://www.elpais.com/articulo/cultura/Facebook/le/gusta/perder/i/griega/elpepucul/20 101115elpepucul_9/Tes> [consulta: 15/07/2011].

«Internet contra la RAE», El Mundo, 26/11/2010. Referencia en línea: <http://www.elmundo.es/elmundo/2010/11/12/cultura/1289557181.html> [consulta: 15/07/2011]. línea:

«Muerte y Resurrección de la letra yeyé», El País, 28/11/2010. Referencia en <http://www.elpais.com/articulo/portada/Muerte/Resurreccion/letra/yeye/elpepusoceps/ 20101128elpepspor_6/Tes> [consulta: 15/07/2011].

«Entrevista digital con Salvador Gutiérrez Ordóñez», El País, 21/12/2010. Referencia en línea: $15 / 07 / 2011]$

$\langle\underline{\mathrm{http}}: / / \mathrm{www}$.elpais.com/edigitales/entrevista.html?encuentro=7506 $>$ [consulta:

«Güisqui no gustó, ¿gustará pirsin?», El País, 02/01/2011. Referencia en línea: <http://www.elpais.com/articulo/sociedad/Guisqui/gusto/gustara/pirsin/elpepisoc/20110 102elpepisoc_1/Tes> [consulta: 15/07/2011].

«Cuidado con las faltas de ortografía en la web!», Mediaelx webdesign, 27/06/2011. Referencia en línea:

$<$ http://www.mediaelx.net/index.php?pag=Noticias\&id=222> [consulta: $15 / 07 / 2011]$.

«Spelling mistakes 'cost millions' in lost online sales», BBC Mobile, 14/07/2011. Referencia en línea: <http://www.bbc.co.uk/news/education-14130854> [consulta: 30/07/2011]. 


\section{PÁGINAS DE FACEBOOK CONSULTADAS ${ }^{13}$}

«(ANTI lenguaje SMS) Esto NO es un SMS, no cuesta nada escribir bien». Referencia en línea: < https://www.facebook.com/pages/ANTI-lenguaje-SMS-Esto-NOes-un-SMS-no-cuesta-nada-escribir-bien/46705394628> [consulta: 28/08/2011].

«Acostarse sólo con gente que no tenga faltas de ortografía». Referencia en línea: $<$ https://www.facebook.com/pages/Acostarse-s\%C3\%B3lo-con-gente-que-no-tengafaltas-de-ortograf\%C3\%ADa/167153526654799> [consulta: 28/08/2011].

«Insumisión a la nueva ortografía de la RAE». Referencia en línea: $<$ https://www.facebook.com/pages/Insumisi\%C3\%B3n-a-la-nueva-ortograf\%C3\%ADade-la-RAE/167552583265812?sk=wall> [consulta: 28/08/2011].

«Me declaro objetor de conciencia de la nueva ortografía de la RAE». Referencia en línea: <https://www.facebook.com/pages/Me-declaro-objetor-de-conciencia-de-lanueva-ortograf\%C3\%ADa-de-la-RAE/116593021737184> [consulta: 28/08/2011].

«Me niego a que "asín", "setiembre" o "almóndiga" estén aceptados por la RAE». Referencia en línea: <https://www.facebook.com/pages/Me-niego-a-que-as\%C3\%ADnsetiembre-o-alm\%C3\%B3ndiga-est\%C3\%A9n-aceptados-por-la-

RAE/120423307979864> [consulta: 28/08/2011].

«Me niego a que la "i griega" pase a llamarse "ye"». Referencia en línea: $<$ https://www.Facebook.com/pages/Me-niego-a-que-i-griega-pase-a-llamarseye/104430506292879? v=wall> [consulta: 28/08/2011].

«Murcianos que quieren que ACHO aparezca en el diccionario de la RAE». Referencia en línea: <https://www.facebook.com/pages/Murcianos-que-quieren-queACHO-aparezca-en-el-diccionario-de-la-RAE/122925734421765> [consulta: 28/08/2011].

«Para que los actuales miembros de la RAE dejen la droga». Referencia en línea: $<$ https://www.facebook.com/pages/Para-que-los-actuales-miembros-de-la-RAE-dejenla-droga/181888121841067> [consulta: 28/08/2011].

«Por la aceptación de la palabra "perroflauta" por la RAE». Referencia en línea: <https://www.facebook.com/pages/Por-la-aceptaci\%C3\%B3n-de-la-palabraperroflauta-por-la-RAE/172837589414307> [consulta: 28/08/2011].

«por los q creen q los acentos y mayusculas son inutiles!». Referencia en línea: $<$ https://www.facebook.com/pages/por-los-q-creen-q-los-acentos-y-mayusculas-soninutiles/372325749838> [consulta: 28/08/2011].

«Sentir un cosquilleo siniestro al mirar horribles faltas de ortografía». Referencia en línea: <https://www.facebook.com/pages/Sentir-un-cosquilleo-siniestro-al-mirarhorribles-faltas-de-ortograf\%C3\%ADa/181351538587640> [consulta: 28/08/2011]. original.

${ }^{13}$ Los nombres de las páginas mantienen, como el resto de ejemplos de Facebook, la ortografía NORMAS. REVISTA DE ESTUDIOS LINGÜÍSTICOS HISPÁNICOS, NÚMERO 1 (AÑO 2011): http://www.uv.es/normas 
«Soy un rebelde, sigo acentuando el "sólo" desafiando a la RAE». Referencia en línea: <https://www.facebook.com/pages/Soy-un-rebelde-sigo-acentuando-els\%C3\%B3lo-desafiando-a-la-RAE/112744848793408> [consulta: 28/08/2011].

«Tus faltas de ortografía me impiden unirme a tu grupo...». Referencia en línea: $<$ https://www.facebook.com/pages/Tus-faltas-de-ortograf\%C3\%ADa-me-impidenunirme-a-tu-grupo/301660249765> [consulta: 28/08/2011].

«Ver tus faltas de ortografía es como echarme ácido sulfúrico en los ojos». Referencia en línea: <https://www.facebook.com/pages/Ver-tus-faltas-deortograf\%C3\%ADa-es-como-echarme-\%C3\%A1cido-sulf\%C3\%BArico-en-losojos/133398040005626> [consulta: 28/08/2011].

«Yo soy de los que escriben los sms con acentos, eñes y puntuación correcta». Referencia en línea: <https://www.facebook.com/pages/Yo-soy-de-los-que-escribenlos-SMS-con-acentos-e\%C3\%B1es-y-puntuaci\%C3\%B3n-correcta/79907089043> [consulta: 28/08/2011].

«Yo también estoy en contra de las nuevas acepciones en la RAE». Referencia en línea: <https://www.facebook.com/pages/Yo-tambi\%C3\%A9n-estoy-en-contra-de-lasnuevas-acepciones-en-la-RAE/195526296675> [consulta: 28/08/2011].

«El mecanismo aleatorio y absurdo que usa la RAE para destruir la lengua». Referencia en línea: <https://www.facebook.com/pages/El-mecanismo-aleatorio-yabsurdo-que-usa-la-RAE-para-destruir-la-lengua/155327281177756> [consulta: 28/08/2011]. 
